\title{
Involving Youth in the Community Development Process ${ }^{1}$
}

\author{
Rosemary V. Barnett and M. A. Brennan ${ }^{2}$ \\ Introduction
}

Program and policy planners need to better understand the role and impact of youth in the community development process. Historically, youth input in decision making, problem-solving, action, and evaluation in communities has received limited attention. However, recent trends suggest that youth are playing an increasingly important role in the development of their communities (Brennan, Barnett, and Lesmeister, 2006).

As nonprofits, volunteer groups, youth programs, and nongovernmental organizations take on larger roles in contributing to local well-being, the active collaboration between youth and adults is vital to the long-term success of development efforts.

Similarly, as community service activities become a more standardized component of high school programs, youth are being given opportunities to become long-term contributors to local development efforts.

There are 8 general steps planners can follow to assist youth in becoming leaders and active participants within their community.

\section{Steps to Take}

\section{Provide youth opportunities to contribute.} Consider new ways to involve youth and allow them to offer input during decision-making, problem solving, and action-taking activities. Active collaboration with youth will engage them in ways that will open doors for them to contribute.

\section{Increase involvement of youth. Present} opportunities for personal self-growth, skill enhancement, and leadership development. Allow youth to work with adults in active collaboration toward local community development. Integrating youth into committees with adults as mentors and guides will enable them to build the leadership skills and personal characteristics necessary for their future adult involvement.

3. Partner with youth. Adults must partner with youth to develop the capacity to serve in organizations and become community leaders. In order to make this a successful venture, adults must first recognize and develop their own existing capacities, motivations, and barriers to partnering with youth. Once existing capacities

1. This document is FCS9253, one of a series of the Department of Family, Youth and Community Sciences, Cooperative Extension Service, Institute of Food and Agricultural Sciences, University of Florida. Publication date: July 2006. Please visit the EDIS website at http://edis.ifas.ufl.edu

2. Rosemary V. Barnett, Assistant Professor of Youth Development and M. A. Brennan, Assistant Professor of Community Development, Department of Family, Youth and Community Sciences, Cooperative Extension Service, Institute of Food and Agricultural Sciences, University of Florida, Gainesville, FL, 32611 
are determined, adult outreach to youth through schools, youth organizations and youth groups can connect adults to youth in order to increase community attachment. Adults can and should inform youth of their value and the need for their service.

4. Engage youth actively. Youth provide new ideas and voices that will stimulate enthusiasm and investment in community structures. In order to engage youth, adults must understand the invaluable impact of youth involvement. This includes respecting youth culture, getting youth involved on all levels, and respecting their invaluable contribution to society. Instead of youth involvement that is strictly limited to task oriented volunteerism, youth should be empowered to become full partners in the community development process. Doing so allows them to establish a vested interest in long-term participation and contribution to their community.

\section{Form connections to teachers. Teachers who} actively engage youth in community issues can increase youth involvement. This may include student government groups, as well as school entrepreneurship and business education organizations that promote local community development by teaching life skills, fiscal responsibility, and leadership. Introducing community needs and opportunities through teachers at area schools reinforces the importance of youth involvement in community action and policy making and will increase local investment and encourage youth participation. Tiebacks to citizenship, political science, and civics education in the community will provide classroom opportunities connected to real world scenarios.

6. Link youth to planning and policy efforts. This can be accomplished by involving youth in the examination of existing policies as well as determining and evaluating potential policy alternatives. By considering youth input into exploration of policy impact, policy alternative criteria for evaluation, and analysis of policy alternative feasibility, youth will move from their role of inactive citizens to fully engaged stakeholders. This powerful connection to real community issues will involve youth not only in present decisions, but in future outcomes, leading them to investments that will provide potential ties toward future commitments as adults.

\section{Allow youth to identify their own interests.} Within the greater social framework of community development and policy making, youth may have expertise or interests in a specific topic. As youth are brought into and connected with organizations and civic roles that they have traditionally been excluded from, they can participate in active and equal decision making at multiple levels. An increased exposure to shared norms and values through discussion on community issues and concerns will engage youth to consider where their interests lie, and encourage them to seek activities where they can create positive change for greater good.

\section{Involve youth in confronting more serious} social problems. This will allow them to see themselves as community development agents capable of transforming their environments. By taking passive citizens waiting for adulthood before they become involved in systemic change and allowing them to be active citizens engaged in the process, youth will have a voice in decisions that transform policies, make institutions more accountable, and affect their lives. This may be reinforced by adult partnerships that value youth and let them know of the importance of their contributions while providing opportunities that build community attachment in order to create a better community in which to live.

\section{Conclusion}

Community development is facilitated by the ability of local people to mobilize resources to address local needs. Youth are in a position to be among the stable and long term contributors that help guide this process. Youth represent a vast and often untapped resource for immediate and long-term community development efforts. They also provide an invaluable resource for program planning and 
effective evaluation. As youth are brought into and connected with organizations and civic roles that they have traditionally been excluded from, they can participate in active and equal decision-making at multiple levels. As youth engage in more sustained positive relationships with adults, other youth, and community organizations, they will learn that they are valued citizens of their communities. Such collaborations will lead to skill enhancement and confidence building traits, which will help prepare them for navigating toward adulthood.

\section{References and Additional Reading}

Barnett, R.V. \& M.A. Brennan. (in press ). "Integrating Youth Into Community Development; Implications for Policy Planning and Program Evaluation. Journal of Youth Development.

Brennan, M.A., R. Barnett, \& M. Lesmeister. (in press)."Enhancing Leadership, Local Capacity, and Youth Involvement in the Community Development Process: Findings from a Survey of StateplaceFlorida Youth".Journal of the Community Development Society.

Sherrod, L.R., Flanagan, C. \& Youniss, J. (2002). Dimensions of Citizenship and Opportunities for Youth Development: The What, Why, When, Where and Who of Citizenship Development. Applied Developmental Science, 6, 4, 264-272. 